\title{
TARGET SETTING FOR INDIRECT PROCESSES: A NEW HYBRID METHOD FOR THE CONTINUOUS IMPROVEMENT MANAGEMENT OF INDIRECT PROCESSES
}

\author{
Sebastian Ihrig \\ TUM School of Management/Bosch Diesel Systems \\ TU Munich/Robert Bosch GmbH; Munich, Germany \\ E-mail: Sebastian.Ihrig@tum.de \\ Alessio Ishizaka \\ Portsmouth Business School \\ University of Portsmouth; Portsmouth, United Kingdom \\ E-mail: Alessio.Ishizaka@port.ac.uk \\ Alwine Mohnen \\ TUM School of Management \\ TU Munich; Munich, Germany \\ E-mail: Alwine.Mohnen@tum.de
}

\begin{abstract}
Indirect processes are increasingly contributing to the total cost of production in highly competitive and technology intensive industries. However, they are less assessable than direct processes due to complex organizational management structures. Companies seeking improvements in indirect areas are therefore demanding for methods to decide where, to which extent and how improvement activities should take place in indirect processes. To facilitate this task, the Target Setting for Indirect Processes (TSIP) method was developed. The development of the method followed the constructive research approach (CRA). It combines the analytic network process (ANP) with methods from managerial accounting research, namely activity-based management, and from the product development area, namely value control chart (VCC), in a kaizen budgeting framework. This new hybrid method was developed and validated in close co-operation with a global first tier automotive supplier.
\end{abstract}

Keywords: Analytic Network Process, Constructive Research Approach, Continuous Improvement, Indirect Processes, Activity Based Management

\section{Introduction}

To decide which process to improve in order to increase the overall performance of any organization is a question of multi criteria decision making. As internal indirect business processes (those that are not characterized by directly value-generating activities, so 'all other processes' in a company that are required to keep the directly value-generating processes running) are characterized by interdependencies, the ANP can be assumed as of general interest in this context (e.g. Horenbeek, Pintelon 2014). Yet improvement project selections for indirect processes in business practice have often been based only on onetime intuitive decisions, or even worse, 'grass cutting' strategies. For example, a required cost reduction goal is determined, then all departments and indirect processes have to International Symposium of the 1

Washington, D.C. Analytic Hierarchy Process June 29 - July 2, 2014 
ISAHP Article: Ihrig, Ishizaka, Mohnen/Target Setting for Indirect Processes: A New Hybrid Method for the Continuous Improvement Management of Indirect Processes, Washington D.C., U.S.A.

contribute at the same level to reach the total reduction goal. By doing this, the fulfillment of customer requirements might be put at risk. For example, trouble spots in the internal supply chain may be affected in a way that they fall below a minimum line. Reasons for this are that indirect processes are less assessable than direct ones as well as the fact that they are less driven by structured and sequential cycles than direct processes. The topic is of high relevance, as indirect processes gain importance, companies are now increasingly seeking structured methods for improvements in indirect areas in specific, especially if there are fewer improvement potentials to be found in direct areas (Deiwiks et al. 2008). Particularly in industries that are characterized by a large share of indirect costs, as often found in high technology and labor-intensive fields, the competition is strong and the topic is of specific interest. To facilitate this task, some might call for external benchmarking. But one has to consider that it can be very time and costconsuming with an unknown outcome (Delpachitra 2008). Furthermore it is very ambiguous to make processes comparable as required especially in indirect areas. Thereby generated benchmark figures might not indicate the best actions. The research question that has lead to the development of the TSIP method therefore was: how to ensure the identification of the right indirect processes to be improved, to which extent and how to reach subordinated target costs. Besides being of great usage in business practice, as demonstrated in the cooperating case organization (passing the weak market test of the CRA), the TSIP method contributes to the general discussion of the application possibilities of ANP, as it demonstrates for example how an ANP output can be used for further goal derivations. Consequently, the conceptualization of the ANP within the TSIP method shall be seen as a starting point and path finder for further research especially in the context of corporate improvement activities.

\section{Objective}

The objective of the study was to develop a practical relevant method with explicit theory linkages, based on empirical groundwork, that enables managers to decide where, to which extent and how improvement activities should take place in indirect business processes to facilitate the achievement of subordinated kaizen targets.

\section{Research Design/Methodology}

The research is based on the CRA proposed by Kasanen et al. (1993) as a unique possibility to solve practice relevant problems while ensuring academic standards and to gain insights that are not accessible with traditional research methods. The steps of this approach are interwoven in the structure of this proposal. In the following the TSIP method development is described in an aggregated form phase by phase. These phases can be accomplished one by one in a single flow, or repeated as possibly required. As input, the required cost reductions need in the sense of a kaizen effort needs to be known. The core idea of the TSIP method is to define the examined indirect processes that are required to keep a defined core process of the company running as alternatives. Based on this the ANP is used to determine the contribution level of each alternative to reach the superior goals of the core process, as well as the ability level of each alternative to realize improvements. A VCC, adopted for the purpose of the method, is then used to derive concrete cost improvement goals based on process related costs.

Phase 1 - Frame: The production process of the cooperating organisation was defined as the core process. It is characterized by value generating activities: underlying idea is that all examined indirect processes are supposed to increase the internal customer ability to 
ISAHP Article: Ihrig, Ishizaka, Mohnen/Target Setting for Indirect Processes: A New Hybrid Method for the Continuous Improvement Management of Indirect Processes, Washington D.C., U.S.A.

serve the external customer. As the criteria to determine the value contribution (priority value) of each alternative depend on the superior goal of the core process, no holistic applicable criteria can be defined. But production can be assumed as a potentially important core process in general. In the cooperating case 'quality' and 'delivery' were defined. In contrast the defined criteria to determine the potential value are applicable in general: 'failure costs', 'cycle time' and 'ability of change'. All criteria have found application in several research projects to evaluate process performances (e.g. Öztayşi, Sari 2012; Johnson 1988) and were confirmed within discussions with the cooperating management. Phase 2 - Process model: In the case organisation 88 indirect processes operated by 9 departments and their respective interdependencies were identified. The alternatives were clustered into 11 main processes, as no expert or group of experts would have been able to evaluate all processes. The following figure visualizes the proceeding:

\begin{tabular}{|c|c|c|c|c|c|c|c|}
\hline & \multicolumn{2}{|c|}{ Department 1} & \multicolumn{2}{|c|}{ Department 2} & \multicolumn{2}{|c|}{ Internal Custome } & \\
\hline & 1.2 & 1.2 & 2.1 & 2.2 & & & \\
\hline $\begin{array}{l}\text { Main Process } 1 \\
\text { Main Process } 2\end{array}$ & s. & & cess & oces & $\begin{array}{c}\text { Core } \\
\text { Process }\end{array}$ & & $\begin{array}{l}\text { External } \\
\text { ustomer }\end{array}$ \\
\hline
\end{tabular}

Figure 1 Schematic process model

Phase 3 - ANP: In the cooperating case each expert had to evaluate first by himself and the judgments were combined afterwards in the sense of a group decision process. Main processes were evaluated by the internal customer and further senior managers, processes under a main process by the respective department managers and the criteria by the senior management. The judgements of the evaluating senior managers (and customers) on the main processes level were weighted corresponding to their consistency factor by using the weighted geometric mean. More specifically, a high consistency factor was interpreted as an indicator for a lack of coherent understanding of the processes (Saaty 2004). Beside this, the evaluating managers on the process level received a recursion request asking for an adaption of their judgments if the consistency factor was larger than 0.1 .

Phase 4 - Process information: The process costs and drivers were collected for two expost and one ex-ante period. The process cost volume for each ex-post period was about 90 million euros. The volume for the ex-ante period slightly lower.

Phase 5 - VCC: The ANP outcomes (priority and potential values of each alternative) and the process costs worked as inputs in an adopted VCC introduced by Brühl (2010). As the number of alternatives was very high, the derivations would have been too ambitious as the VCC suggests to adjust nearly all processes except those positioned on (respectively close to) the angle bisector. Therefore the adopted VCC idea was extended: as all processes are required to keep the core process running and the level of value contribution of any process needs no improvement, those located below the angle bisector should partly subsidize those above in respect to their required cost reduction level. The proceeding is demonstrated in figure 2: $\mathrm{C}$ and $\mathrm{B}$ help to subsidize the reduction need of A and D in the first step of subsidization (1.); therefore $\mathrm{C}$ and $\mathrm{B}$ shall not increase their costs. In the next step the potential of D and A is considered as well (2.), using the rule of three. Based on the results different paths to reach the reduction goals (3.) were calculated (whether by a reduction of the cost driver, the process cost or a combination of both). The aggregation of the results on a main processes and department level was of special interest for the managers.

International Symposium of the 
ISAHP Article: Ihrig, Ishizaka, Mohnen/Target Setting for Indirect Processes: A New Hybrid Method for the Continuous Improvement Management of Indirect Processes, Washington D.C., U.S.A.
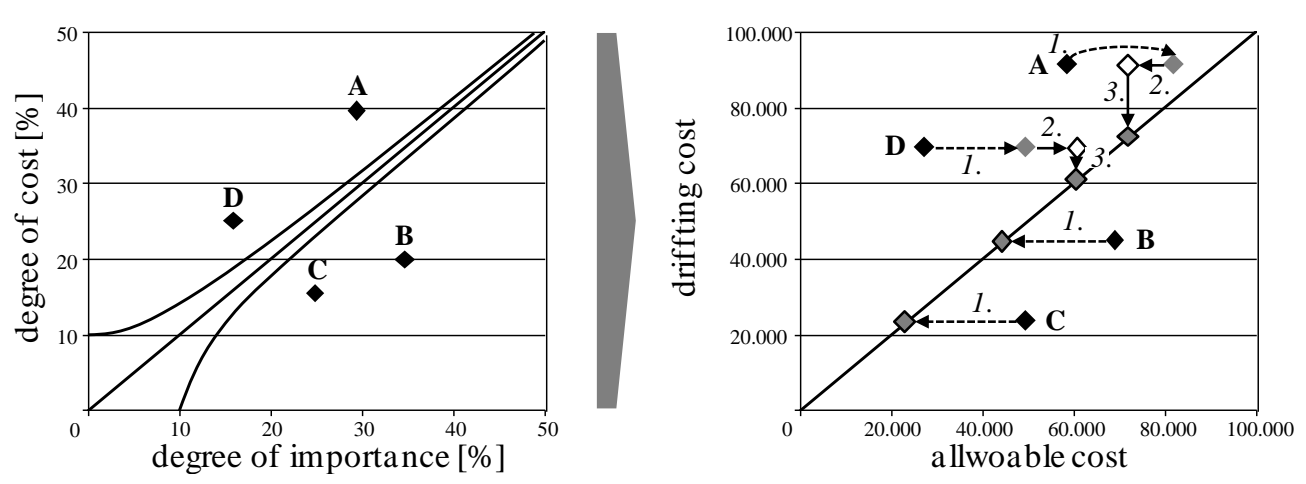

Figure 2 Schematic transformation of a VCC (left) into an extended adopted VCC (right)

\section{Data/Model Analysis}

The following illustration shows schematically the ANP of the cooperating case (interdependencies between processes are represented by the bow arrows, which are actually different under each criterion). The priority and potential values are not combined as the resulting priorities would not have any value (indicated by the scattered connection).

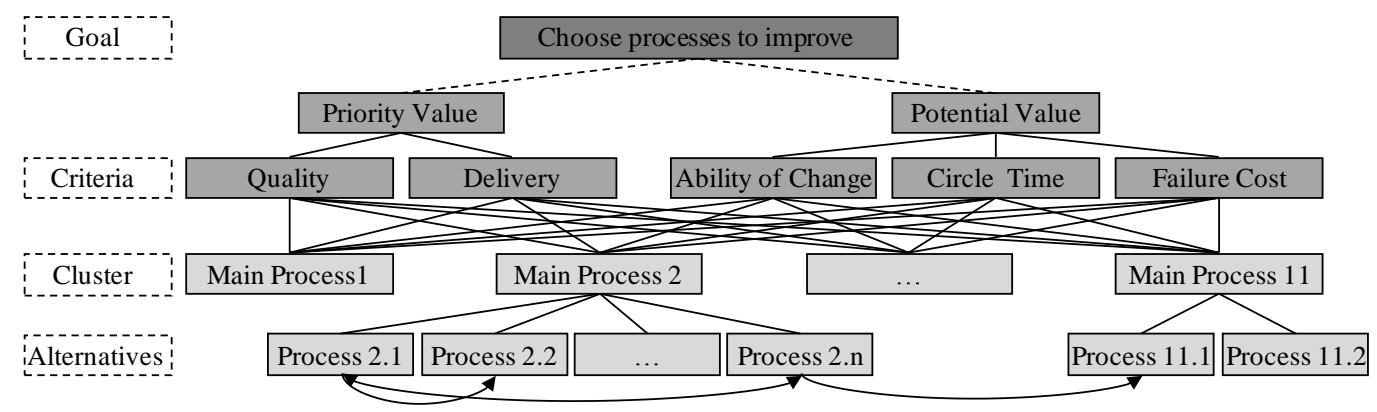

Figure 3 Schematic ANP of the case

To design the ANP, an own network was set up with SuperDecisions for each criterion. The priority values of the alternatives were combined afterwards based on the priority values of the criteria. To compensate a recursion within the underlying super matrix, which generated no valuable outputs, it was necessary to connect all alternatives in the process cluster to the goal cluster. The consideration of the inner dependence under the potential criteria required an inverting of the primary judgments first; afterwards the priority values were inverted again. The following illustration shows as an example the judgment matrices of the main process ' 3 . Order Procedure' evaluated by one department manager under the 'quality' criteria.

Table 1 Comparisons under the main process '3. Order Procedure' regarding 'quality'

\begin{tabular}{|c|c|c|c|c|c|c|}
\hline 3. Order Procedure & 3.1 & 3.2 & 3.3 & 3.4 & Priorities & $\mathrm{CR}$ \\
\hline 3.1 Product Planning & 1 & 6 & 1 & $1 / 3$ & 0.20086 & \multirow{4}{*}{0.07911} \\
\hline 3.2 Production Scheduling & $1 / 6$ & 1 & $1 / 6$ & $1 / 7$ & 0.04532 & \\
\hline 3.3 Material Ordering & 1 & 6 & 1 & $1 / 5$ & 0.18278 & \\
\hline 3.4 Change Management & 3 & 7 & 5 & 1 & 0.57104 & \\
\hline $\begin{array}{l}\text { International Symposium of the } \\
\text { Analytic Hierarchy Process }\end{array}$ & & 4 & & & June 2 & $\begin{array}{l}\text { ngton, D. C } \\
\text { July } 2,2014\end{array}$ \\
\hline
\end{tabular}


ISAHP Article: Ihrig, Ishizaka, Mohnen/Target Setting for Indirect Processes: A New Hybrid Method for the Continuous Improvement Management of Indirect Processes, Washington D.C., U.S.A.

\section{Limitations}

The priority values of the alternatives are only valid in the context of continuous improvement. Radical cost reductions might require a redesign of the processes, making the process structure and evaluations obsolete. In such a situation, repetitions of some phases of the TSIP method would be required. Irrespective of clustering the alternatives, the number of required pair wise comparisons can still be high. To overcome this, further cluster levels can be set up, but the abstraction level will increase at the same time.

\section{Conclusions}

As doubts have been expressed whether ANP is able to generate cardinal scaled outputs, the possibilities to derive concrete reduction goals beyond the simple selection of alternatives within the TSIP method should be pointed out. In addition the suggested ANP design allows comparisons in situations where not all alternatives can be compared by one (group of) expert(s) due to a lack of knowledge about the alternatives, even though they are still homogeneous enough to be compared. These circumstances might open the door for a broader application field of the ANP in organizational research. Considering the extended adopted VCC, the TSIP method furthermore contributes to the discussion concerning the use of the ANP in the context of performance measurement (perceived as quantifying the efficiency of an action where efficiency relates to the required effort to reach a defined value contribution). The TSIP method has been used once within the cooperating organization and it was decided that it will continue to be used within the upcoming planning process. If proven valid, it might even find application within the whole corporate group. In respect to the external validity, it shall be pointed out that the required case-by-case specifications for further applications have been reduced to a minimum. As the method was primarily designed to analyze processes serving an internal customer, an application towards external customers will also be of interest in the future.

\section{Acknowledgement}

We are grateful to Rozann Whitaker Saaty for her advices on using SuperDecisons.

\section{Key References}

Brühl, R. (2010). Kennzahlen für die Zielkostenkontrolle. ZP, 21 (1), 117-128.

Deiwiks, J. \& Faust, P. \& Becker, H.-H. \& Niemand, S. (2008). Lean im indirekten Bereich. Leitlinien, Methoden und Erfolgsfaktoren. zfo, 77 (6), 402-411.

Delpachitra, S. (2008). Activity Based Costing and Process Benchmarking: An Application to General Insurance. Benchmarking: An International Journal, 15 (2), 137-147.

van Horenbeek, A. \& Pintelon, L. (2014). Development of a maintenance performance measurement framework - using the analytic network process (ANP) for maintenance performance indicator selection. Omega, 42 (1), 33-46.

Johnson, T.H. (1988): Activity-Based Information: A Blueprint for World-Class Management Accounting. Management Accountig, (June), 23-30.

Kasanen, E. \& Lukka, K. \& Siitonen, A. (1993): The Constructive Approach in Management Accounting Research. JMAR, 5 (Fall), 243-264.

Öztayşi, B. \& Sari, İ.U. (2012). Performance measurement of a manufacturing company using fuzzy analytical network process. IJAM, 4 (4), 439-459.

Saaty, T.L. (2004). Fundamentals of the Analytic Network Process - Dependence and Feedback in Decision-Making with a Single Network. JSSE, 13 (2), 129-157.

International Symposium of the 